\title{
ON APPROXIMATION BY PHILLIPS TYPE MODIFIED BERNSTEIN OPERATOR IN A MOBILE INTERVAL
}

\author{
Minakshi Dhamija, Ryozi SaKai and NaOKAnt DeO
}

Abstract. In the present paper we study a Phillips type modified Bernstein operator $M_{n}$, where the function is defined in the mobile interval $\left[0,1-\frac{1}{n+1}\right]$ and obtain its $m-t h$ order moment. We establish some direct results in simultaneous approximation for this modified Bernstein operator.

Mathematics subject classification (2010): 41A25, 41A36.

Keywords and phrases: Bernstein operator, Phillips operator, Simultaneous approximation, direct results, mobile interval.

\section{REFERENCES}

[1] S. N. Bernstein, Démonstration du théoréme de Weierstrass fondée sur le calcul de probabilités, Commun. Sco. Math. Charkov, 13 (2), 1912, 1-2.

[2] N. DEO, Some approximation for the linear combinations of modified Beta operators, AJMAA, 2 (2), Article 4, 2005, 1-12.

[3] N. DEO, Direct result on the Durrmeyer variant of Beta operators, SEA. Bull. Math., 32 (2008), 283-290.

[4] N. DEO, Direct result on exponential-type operators, Appl. Math. Comput., 204 (2008), 109-115.

[5] N. Deo, M. A. Noor And M. A. Siddiqui, On approximation by a class of new Bernstein type operators, Appl. Math. Comput., 201 (2008), 3951-3958.

[6] Z. Finta And V. Gupta, Direct and inverse estimates for Phillips type operators, J. Math. Anal. Appl., 303 (2005), 627-642.

[7] M. S. FLOATER, On the convergence of derivatives of Bernstein approximation, J. Approx. Theory, 134 (2005), 130-135.

[8] H. GONSKA AND I. RASA, Asymptotic behaviour of differentiated Bernstein polynomials, Mat. Vesnik 61 (2009), 53-60.

[9] H. Gonska, M. Heilmann And I. Ras A, Asymptotic behaviour of differentiated Bernstein polynomials revisited, General Mathematics (Sibiu) 18 (2010), 45-53.

[10] H. Gonska, M. Heilmann And I. Ras A, Kantorovich operators of order $k$, Numer. Funct. Anal. Optimiz. 32 (2011), 717-738.

[11] V. GUPTA, Error estimation for mixed summation-integral type operators, J. Math. Anal. Appl., 313 (2) (2006), 69-81.

[12] V. Gupta, P. N. Agrawal, And H. Karsli, Simultaneous approximation for the Phillips-Bézier operators, JIPAM, 7 (4) (2006), Art. 141, 1-7.

[13] V. GUPTA AND O. DOGRU, Direct results for certain family of Integral type operators, JIPAM, 6 (1), Art. 21, 2005, 1-11.

[14] V. GUPTA AND N. ISPIR, On simultaneous approximation for some modified Bernstein-type operators, IJMMS, 71 (2004), 604-612.

[15] V. Gupta And J. SinHa, Direct results on certain Szasz-Mirakyan operators, Appl. Math. Comput. 195 (2008), 230-239.

[16] H. S. Jung, N. Deo And M. Dhamija, Pointwise approximation by Bernstein type operators in mobile interval, Appl. Math. Comput., 214 (1) (2014), 683-694. 